\title{
A three year follow up of self expanding metal stents in the endoscopic palliation of longterm survivors with malignant biliary obstruction
}

\author{
S O’Brien, A R W Hatfield, P I Craig, S P Williams
}

\begin{abstract}
Effective palliation of malignant biliary obstruction with conventional 10 or 12 French gauge straight polyethylene endoprostheses is limited by stent occlusion, which typically occurs four to five months after insertion. Short term follow up studies of self expanding metal stents (Wallstent, Schneider, UK) in the treatment of patients with malignant biliary obstruction have shown that their use is associated with fewer episodes of stent occlusion compared with plastic stents. There are few data, however, on the longterm patency and durability of metal stents in malignant disease. Between May 1989 and May 1992, metal stents were inserted in 28 patients with malignant bile duct strictures secondary to ampullary tumour $(n=10)$, pancreatic carcinoma $(n=10)$, cholangiocarcinoma $(n=7)$, and porta hepatis nodes from colorectal carcinoma $(n=1)$. The follow up of these patients until May 1993 is reported with a median follow up of 14.6 months. Twenty two of $28(78.6 \%)$ patients remained free of jaundice or cholangitis. The median period of stent patency was $8 \cdot 2$ months (range $1 \cdot 0-32 \cdot 5$ ). Thirteen patients represented with jaundice or cholangitis and endoscopic retrograde cholangiopancreatography showed evidence of stent occlusion due to tumour ingrowth. Successful clearance of metal stents was achieved by balloon trawling, or insertion of a polyethylene stent. In conclusion, metal stents provide improved longterm palliation for patients with malignant biliary strictures with fewer episodes of occlusion compared with conventional stents.
\end{abstract}

(Gut 1995; 36: 618-621)

Keywords: bile duct diseases, bile duct obstruction, stents, endoscopic retrograde

cholangiopancreatography.

Gastroenterology, The Middlesex Hospital, London

$S$ O'Brien

A R W Hatfield

P I Craig

S P Williams

Correspondence to: Dr A R W Hatfield

Department of

Gastroenterology, The

Middlesex Hospital, London NW1 8 AA.

Accepted for publication 15 July 1994
The endoscopic stenting of patients with unresectable malignant biliary obstruction with 10 and 12 French gauge (FG) polyethylene endoprostheses is now commonplace. ${ }^{1-3}$ The development of stent occlusion, however, in $20-30 \%$ of patients within three months of stent insertion is an important problem with this approach to treatment. ${ }^{4}$
Self expanding metal stents (Wallstents) may be inserted percutaneously or endoscopically and have been used in the treatment of patients with malignant biliary obstruction since 1989..$^{5-7}$ Self expanding metal stents have a longer patency than polyethylene stents in short term follow up, however, the longterm patency of metal stents is unknown. ${ }^{8-11}$ Furthermore, as most patients stented for malignant biliary obstruction will die with their first stent in situ one of the important issues regarding the use of metal stents in this population of patients is the question of cost effectiveness. ${ }^{9} 1112$

The aim of this study was to assess the longterm efficacy and complications of metal stents in the treatment of patients with unresectable malignant biliary strictures.

\section{Methods}

\section{PATIENTS}

Between may 1989 and May 1992, metal stents were inserted in 28 patients (median age 66 years, range 40-80) with unresectable malignant biliary obstruction (Table I). Bile duct obstruction was secondary to pancreatic carcinoma in 10 patients, ampullary carcinoma in 10 patients, cholangiocarcinoma in seven patients, and extrinsic compression of the biliary tree from secondary carcinoma in one patient. The cholangiocarcinoma was located high in the bile duct in six patients and low in the bile duct in one patient. The median time from diagnosis of malignant bile duct stricture to insertion of a metal stent was six months (range 1-72) and the median number of polyethylene stents inserted during this time period was two (range 0-12) (Table I).

\section{METAL STENT INSERTION}

A metal stent (Wallstent, Schneider, UK) is made of surgical grade stainless steel alloy

TABLE I Patients clinical data $(n=28)$

\begin{tabular}{ll}
\hline Age (y) median (range) & $66(40-80)$ \\
Male:female & $17: 11$ \\
Nature of lesion & 10 of 28 \\
$\quad$ Ampullary & 10 of 28 \\
Pancreatic & 7 of 28 \\
Cholangiocarcinoma & 1 of 28 \\
Extrinsic & 6 of 7 \\
Location of cholangiocarcinoma & 1 of 7 \\
$\quad$ High & $6.0(1-72)$ \\
$\begin{array}{l}\text { Time from diagnosis to metal stent insertion } \\
\text { (month) median (range) }\end{array}$ & $2 \cdot 0(0-12)$ \\
$\begin{array}{l}\text { Polyethylene stents previously inserted } \\
\text { median (range) }\end{array}$ & \\
\hline
\end{tabular}




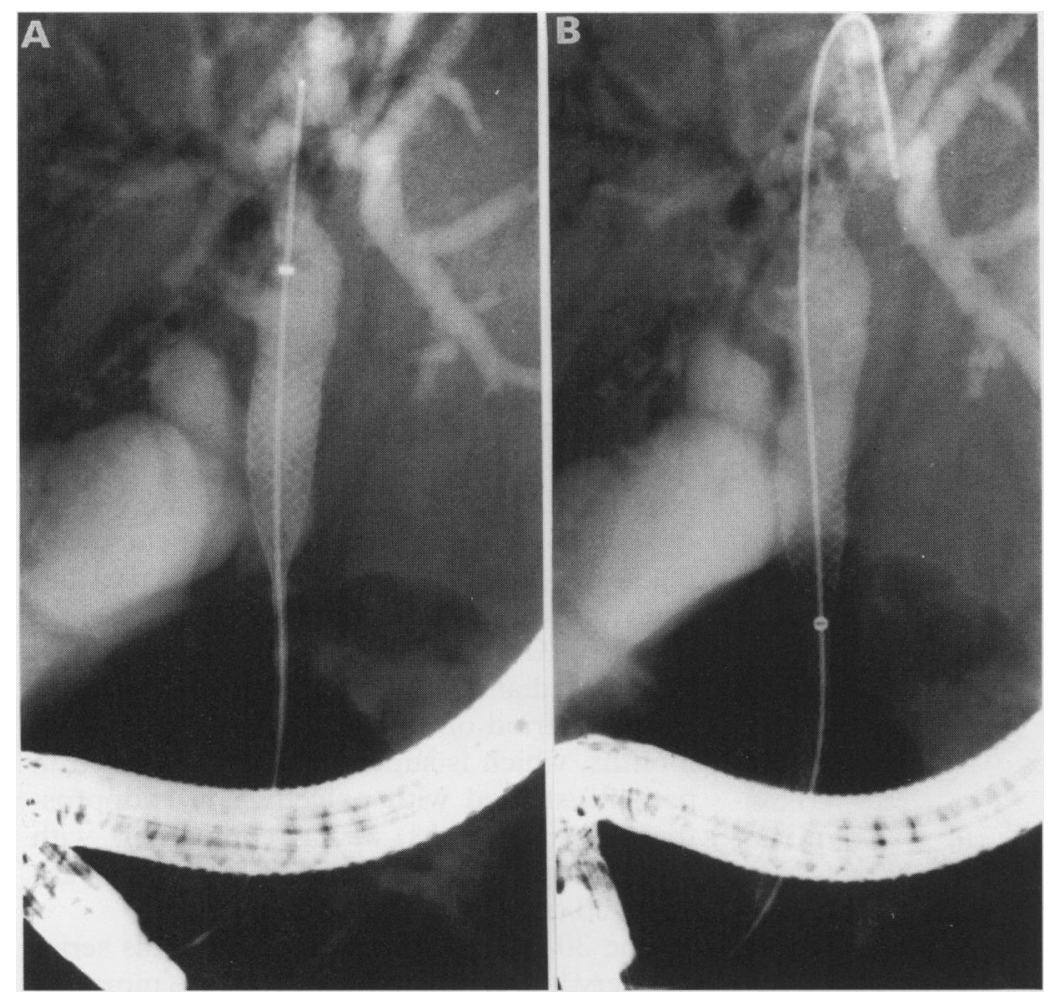

Figure 1: Endoscopic insertion of a metal stent. (A) Partially released metal stent in position across a distal bile duct stricture secondary to pancreatic malignancy; (B) metal stent almost completely released. until death or stent failure requiring surgical intervention. Patients were readmitted for endoscopic retrograde cholangiopancreatography if there was clinical evidence of metal stent occlusion (that is, the development of symptoms of jaundice or cholangitis). The follow up of these 28 patients until May 1993 is reported.

\section{Results}

METAL STENT PATENCY

The median period of stent patency for the 28 patients was $8 \cdot 2$ months (range $1 \cdot 0-32 \cdot 5$ ). The median follow up was 14.6 months (range $1 \cdot 0-38 \cdot 5)$ and at this stage 22 of $28(78 \cdot 6 \%)$ patients with malignant disease remained free of jaundice or cholangitis (Table II). There was no clinical evidence of stent occlusion in 15 of 28 patients throughout the total follow up period of up to 38.5 months.

Thirteen patients $(46.4 \%)$ with malignant disease developed symptomatic metal stent occlusion as evidenced clinically by jaundice or cholangitis, or both at a median of 6.4 months $(4-30 \cdot 4)$. The median follow up time of the group of patients who developed metal stent occlusion was not significantly different from that of the group who did not develop metal stent occlusion, $14 \cdot 1$ months (range $5 \cdot 1-38 \cdot 5$ ) and 12.0 months (range $1 \cdot 0-32 \cdot 7$ ) respectively (Table II). The number of patients with cholangiocarcinoma treated with external beam radiation or iridium implants, or both was comparable in both groups.

Ten of 13 patients with symptomatic metal stent occlusion were examined with a mother and baby scope and had further endoscopic intervention. Of the remaining three patients, one patient was terminally ill, one patient had an early elective Whipple's procedure performed, and the third patient declined endoscopic intervention. Jaundice and fever subsequently settled in this patient with antibiotics and rehydration.

Balloon trawling of the metal stent was performed in four patients at a median of $9 \cdot 2$ months to remove sludge and debris above soft frond like tumour invasion of the stent. Three of the four patients did not have any further episodes of stent occlusion after a further median follow up of 8.5 months. Stent reocclusion occurred in one patient after two months and a polyethylene stent was inserted. In the other six patients the major cause of metal stent occlusion was the presence of more solid tumour occupying the stent lumen. In these six patients a polyethylene stent was inserted through the metal stent after a median of seven months. Stent reocclusion occurred in three of six patients after a median of three months requiring a change of the polyethylene stent.

SURVIVAL AND COMPLICATIONS

The median survival of the 28 patients with malignant bile duct obstruction was $15 \cdot 1$ months $(1 \cdot 0-38 \cdot 5)$. By May 1993, 24 of 28
PATIENT FOLLOW UP

All patients were followed up, by regular outpatient clinic visits (one, three, or six monthly as appropriate) or by communication with general practitioners or referring physicians, 


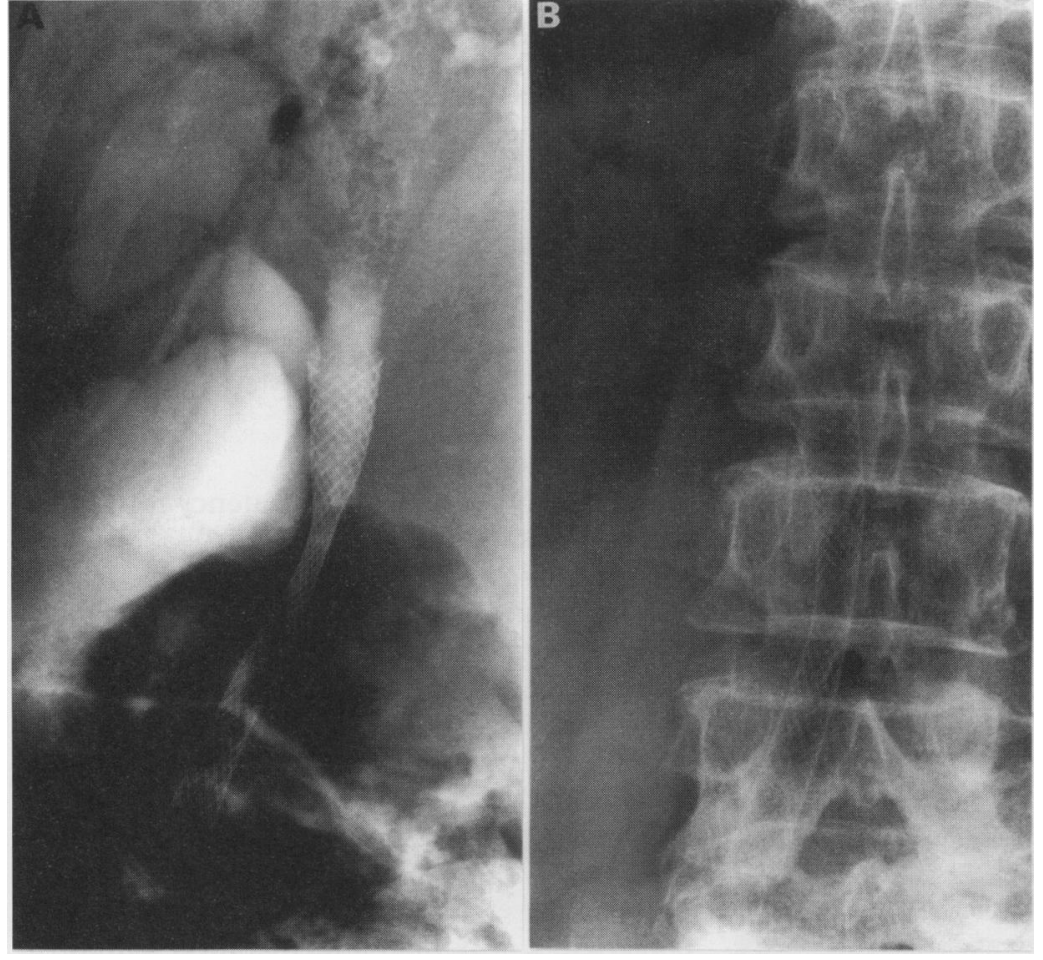

Figure 2: Endoscopic insertion of a metal stent. (A) Appearance of metal stent after complete release across bile duct stricture; (B) metal stent completely expanded one week after insertion. expanding metal stents has permitted the endoscopic insertion of prostheses, which ultimately have a considerably larger internal diameter. The Wallstent is loaded on a 9 FG delivery system, with the result that it is comparatively easy to insert and position and when released in situ it expands to a maximum internal diameter of $1 \mathrm{~cm}$. Although difficulty with stent insertion has been reported by some authors, ${ }^{15}$ the success rate for the insertion of metal stents in the present series was $100 \%$. In addition, technical problems with stent deformity or migration were not found and post-stenting cholangitis was not seen. ${ }^{16} 17$

The use of metal stents in patients with malignant biliary obstruction in this series has been associated with very favourable results with $78.6 \%$ of patients remaining jaundice free after a median follow up of 14.6 months. The median period of metal stent patency was $8 \cdot 2$ months, which is superior to that expected in patients stented with polyethylene endoprostheses (4-5 months) and is comparable with metal stent patency reported in recent randomised controlled trials. ${ }^{10-11}$

The 30 day mortality of $3.5 \%$ in this series was very low compared with $10-14 \%$ mortality in other series. ${ }^{11} 18$ The overall survival of patients treated with metal stents in this study was longer than that reported in other series ${ }^{11} 17$ and is attributable both to the lower proportion of patients with pancreatic carcinoma in this series together with our policy of careful patient selection for this form of treatment.

Episodes of symptomatic metal stent occlusion were easily treated endoscopically with either balloon trawling of the metal stent to remove biliary sludge and debris or by the insertion of a polyethylene stent through a tumour occluded metal stent lumen. The patency rates for polyethylene stents used in this situation were similar to those seen in other studies. $^{9-11}$ In addition $50 \%$ of these patients who required further endoscopic intervention with balloon trawling or stenting did not have any further episodes of stent occlusion over subsequent follow up.

At a retail cost of $£ 475$ (+value added tax), a Wallstent is expensive compared with other forms of treatment for patients with malignant bile duct obstruction - that is, a Wilson Cook polyethylene endoprosthesis costs $£ 26.70$ (+value added tax). The current cost of a short admission for any stenting procedure at the Middlesex Hospital is about $£ 1200$. Thus, considering the expense of repeated hospital admissions for polyethylene stent changes, the use of metal stents may prove to be very cost effective in patients who live long enough to need one or more admissions for stent blockage.

The occlusion of stents with biliary sludge is the major problem with the use of polyethylene endoprostheses in the treatment of patients with unresectable malignant biliary obstruction. ${ }^{4}$ The internal diameter of a stent has been shown to be a critical factor in the development of stent occlusion. ${ }^{1314}$ The maximum possible diameter of the prosthesis, however, which may be inserted is determined by the diameter of the endoscope instrumentation channel. Therefore the development of self
TABLe II Patient follow up $(n=28)$

\begin{tabular}{lc}
\hline Survival (month) median (range) & $15 \cdot 1(1 \cdot 0-38 \cdot 5)$ \\
Metal stents patent (\%) at median follow up & \\
$\quad 14 \cdot 6$ months & $22(78 \cdot 6)$ \\
$\begin{array}{l}\text { Median stent patency (month) } \\
\text { Patients with metal stent occlusion (\%) }\end{array}$ & $13 \cdot 2(1 \cdot 0-32 \cdot 5)$ \\
$\begin{array}{l}\text { Follow up time of patients with metal stent } \\
\text { occlusion (month) median (range) }\end{array}$ & $14 \cdot 1(5 \cdot 1-38 \cdot 5)$ \\
$\begin{array}{l}\text { Follow up time of patients without metal } \\
\text { stent occlusion (month) median (range) }\end{array}$ & $12 \cdot 0(1 \cdot 0-32 \cdot 7)$ \\
\hline
\end{tabular}


In a recent study from our unit, $67 \%$ of patients died with their initial polyethylene stent in situ and only 33\% needed readmission for a stent change at a mean of 4.5 months. ${ }^{12}$ It is therefore not economical to put metal stents into all patients presenting with malignant obstructive jaundice as most would be successfully palliated with a single polyethylene stent. Ideally the longer term survivors should be selected out for metal stent insertion. In practice this is difficult and our policy is to place metal stents in patients we judge to have a better prognosis - that is, patients with an unresectable ampullary tumour or a cholangiocarcinoma. Those patients with pancreatic adenocarcinoma who show little evidence of disease progression, when they represent for their first conventional stent change, we would also consider for insertion of a metal stent.

In conclusion, metal stents give prolonged palliation and superior results compared with polyethylene stents in patients with unresectable malignant biliary obstruction. To optimise cost effectiveness it is essential that patients are carefully selected for this form of treatment.

1 Cotton PB. Endoscopic methods for relief of malignan obstructive jaundice. World $\mathcal{f}$ Surg 1989; 8: 854-61.

2 Huibregtse $\mathrm{K}$. Endoscopic biliary and pancreatic drainage. Stuttgart: Georg Thieme Verlag, 1988.

3 Speer AG, Cotton PB, Russell RC, Mason RR, Hatfield $\mathrm{AR}$, Leung JW, et al. Randomised trial of endoscopic versus percutaneous stent insertion in malignant obstructive jaundice. Lancet 1987; ii: 57-62.

4 Huibregtse K, Katon RM, Coene PP, Tytgat GNJ. Endoscopic palliative treatment in pancreatic cancer Gastrointest Endosc 1986; 32: 334-8.
5 Irving JD, Adam A, Dick R, Dondelinger RF, Lunderquist A, Roche A. Gianturco expandable metallic biliary stents: results of a European clinical trial. Radiology 1989; 172: 321-6.

6 Huibregtse K, Cheng J, Coene PP, Fockens P, Tytgat GN. Endoscopic placement of expandable metal stents for biliary strictures - a preliminary report on experience with 33 1ary strictures - a preliminary report on

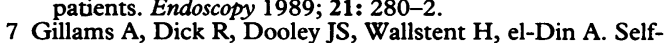
expandable stainless steel braided endoprosthesis for biliary strictures. Radiology 1990; 174: 137-40.

8 Huibregtse K, Carr-Locke DL, Cremer M, Domschke W, Fockens P, Foerster E, et al. Biliary stent occlusion - a problem with self-expanding metal stents. Endoscopy 1992; 24: 391-4.

9 Knyrim K, Wagner HJ, Pausch J, Vakil N. A prospective, randomized, controlled trial of metal stents for malignant obstruction of the common bile duct. Endoscopy 1993; 25: 207-12.

10 Wagner HJ, Knyrim K, Vakil N, Klose KJ. Plastic endoprostheses versus metal stents in the palliative treatment of malignant hilar biliary obstruction. A prospective and randomized trial. Endoscopy 1993; 25: 213-8.

11 Davids PH, Groen AK, Rauws EA, Tytgat GN, Huibregtse $K$. Randomised trial of self-expanding metal stents versus polyethylene stents for distal malignant biliary obstruction. Lancet 1992; 340: 1488-92.

12 Smith AC, Dowsett JF, Russell RCG, Hatfield ARW. Total hospital stay (THS) and endoscopic stent replacement in primary malignant low bile duct obstruction. Gut 1990; 31: A1 181 .

13 Speer AG, Cotton PB, MacRae KD. Endoscopic management of malignant biliary obstruction: stents of 10 French gauge are preferable to stents of 8 French gauge. Gastrointest Endosc 1988; 34: 412-7.

14 Siegal JH, Pullano WE, Wright G. The ultimate large calibre endoprosthesis, F Poisseuille was right, bigger is better. Gastrointest Endosc 1985; 31: 158-9.

15 Bethege N, Wagner HJ, Knyrim K, Zimmermann HB Starck E, Pausch J, et al. Technical failure of biliary metal stent deployment in a series of 116 applications. Endoscopy 1992; 24: 395-400.

16 Morita S. Biliary endoprosthesis of malignant biliary obstruction using expandable metallic stent - preliminary clinical experience. Nippon Igaku Hoshasen Gakkai Zassh 1992; 52: 623-40.

17 Salomonowitz EK, Adam A, Antonucci F, Stuckmann G, Zollikofer CL. Malignant biliary obstruction: treatment with self-expandable stainless steel endoprosthesis. Cardiovasc Intervent Radiol. 1992; 15: 351-5.

18 Lee MJ, Dawson SL, Mueller PR, Krebs TL, Saini S, Hahn PF. Palliation of malignant bile duct obstruction with metallic biliary endoprosthesis: technique, results and metallic biliary endoprosthesis: technique, results
complications. $\mathcal{F}$ Vasc Interv Radiol 1992; 3: 665-71. 